\title{
Señderes
}

\section{Alteridad: rasgo de la subjetividad política de maestros y respuesta ética en la acción educativa'}

\author{
Otherness: trait of teacher policy subjectivity \\ and ethics response in educational action
}

Una subjetividad genuinamente humana es una subjetividad desde la alteridad, en la alteridad y para la alteridad.

Mèlich (2000)

\begin{abstract}
Autores
Lina Raquel Restrepo Aristizábal²

Recibido: 16 de mayo de 2017.

Aprobado: 30 de noviembre de 2017.
\end{abstract}

\section{Resumen}

Este artículo presenta la alteridad como uno de los rasgos de la subjetividad política de maestros, se parte de la tesis según la cual la alteridad se configura biográficamente en experiencias que implican hacerse responsable del otro, experiencias que le permiten al maestro tejer el mundo compartido a través de acciones políticas en el aula; un hallazgo que se centra en el relato autobiográfico de los maestros que participaron en la investigación, de la cual hace parte este artículo. El texto ofrece, además, una mirada a la educación como acción política que requiere una relación de acogida y reconocimiento de la singularidad y distinción del otro, para desde allí construir el mundo compartido. Finalmente, se presentan las implicaciones de una acción educativa fundada en el principio de la alteridad, con el fin de empoderar a los maestros de su capacidad para emprender acciones nuevas con palabras y actos. 
Palabras clave: alteridad; educación; ética; política; subjetividad política.

\begin{abstract}
This article presents otherness as one of traits of teacher political subjectivity. It is based on the thesis according to which otherness is biographically configured in experiences that involve taking responsibility for the other. Such experiences allow teachers hatching the world we share through political actions in the classroom. This finding focusses on the autobiographical account of the teachers who took part in the research, of
\end{abstract}

which this article is a result. The text also offers a look at education as a political action that requires a relationship of acceptance and recognition of the other uniqueness and distinction, and based on it to build the shared world. Finally, the article exhibits the implications of educational action founded on the principle of otherness, in order to empower teachers with the ability to take new actions with words and acts.

Key words: Otherness; education; ethics; politics; political subjectivity

\section{Introducción}

Este artículo hace parte de la investigación "Sentidos entre-tejidos: una aproximación a la subjetividad política en maestros y maestras”, la cual buscó comprender cómo se han venido configurando las subjetividades políticas de maestros y maestras de diferentes instituciones educativas públicas de la ciudad de Medellín. Con esta investigación se pretendía aportar a la reflexión teórica y práctica de los maestros ${ }^{3}$ como sujetos de acción política, que desde la práctica del aula aportan a la construcción de un mundo compartido en el que pueden emprenderse transformaciones desde los escenarios cotidianos y en el cual la escuela pueda convertirse en una esfera pública que reconozca la pluralidad, la alteridad, la participación y la libertad como fundamentos de la vida en común.

Durante el ejercicio de investigación, y a partir de la lectura de los relatos y los acontecimientos vitales de los participantes, se construyó el hallazgo fundamental de la investigación, el cual sostiene que la subjetividad política de los maestros participantes se configura a partir de cuatro rasgos: pluralidad, conciencia histórica, alteridad y resistencia, los cuales se entretejen de manera particular según los acontecimientos biográficos de cada sujeto, en los que uno de los rasgos actúa como el que nuclea y permite la emergencia de los demás, teniendo siempre a la pluralidad como condición y punto de partida.

De manera particular, este texto se centra en la alteridad como rasgo de la subjetividad política a partir de los relatos autobiográficos de los maestros participantes, en especial el relato de Amalia ${ }^{4}$, por medio de la tesis según la cual la alteridad es un rasgo de la subjetividad política que se configura biográficamente en experiencias que implican hacerse responsable del otro y le permiten al sujeto (maestro) tejer el mundo

3 En adelante, cada vez que se hable de maestros también se incluyen las maestras.

4 Los nombres de los participantes fueron cambiados para proteger su identidad. 
compartido a través de acciones políticas (en el aula). El propósito de este texto, entonces, es presentar cómo se configura la subjetividad política de los maestros participantes a través de la alteridad y cómo a partir de allí puede constituirse la acción educativa como acción política.

En este sentido, las preguntas que convocan esta reflexión son: ¿Cómo se configura la subjetividad política de los maestros a partir del principio ético de la alteridad? ¿Cómo aportar a la comprensión de la acción educativa desde la alteridad? ¿Por qué responder de manera ética a la existencia del otro, en el escenario de la escuela, es una acción política? Estas reflexiones se presentan en los siguientes apartados: antecedentes y referentes teóricos sobre la subjetividad política, la acción política y la alteridad, el diseño metodológico, los sentidos de la alteridad en la narrativa de los maestros participantes y, finalmente, las implicaciones de concebir la educación como acción política fundada en el principio ético de la alteridad.

Esta investigación surge del interés por reconocer la escuela como escenario político, de debate y de recuperación del sujeto, para enfrentar las lógicas deshumanizadas que se evidencian día a día, además por la necesidad de visibilizar el trabajo que en este sentido vienen realizando muchos maestros que están aportando de manera decidida a la formación de sujetos políticos, para hacer de la escuela un espacio democrático y participativo.

En el rastreo de los antecedentes se encontraron investigaciones que abordaban la categoría de la subjetividad política con distintos grupos poblacionales y en distintos escenarios. Entre ellas se resaltan aquellas que estudian la configuración de sujetos políticos, en jóvenes (Alvarado, Ospina, Botero y Muñoz, 2008), en niños (Roldán, 2006) y en el contexto escolar (Prada et al., 2006). También se rastrearon estudios que tienen al maestro como el eje central de su interés investigativo. Los temas de estas investigaciones tienen relación con la eticidad y la subjetividad (Patiño y Rojas, 2009); la construcción de la ética (Poujol, 2004); la identidad y la memoria (Mórtola, 2006); las intersecciones que se presentan entre la vida personal, profesional y político-sindical (Loyo y Rodríguez, 2007); la reflexión en la acción de los docentes (Barilá, Fabri, y Castillo, 2008; Bedacarratx, 2009), y el maestro y las políticas públicas (Díaz-Barriga e Inclán, 2001).

El tema de la subjetividad política de maestros es trabajado de manera específica por Martínez (2006), quien centra su interés en comprender cómo los maestros se configuran como sujetos políticos a partir de las redes pedagógicas, las cuales surgen como resistencia ante las imposiciones externas que los ubican en un lugar de receptores. Esta autora sostiene que los procesos de empobrecimiento en los entornos sociales y políticos, como la formación por competencias y la ausencia de memoria y de utopías, erosionan la construcción de subjetividades desde lógicas funcionales a las demandas del mercado, las cuales niegan toda posibilidad de una subjetividad constituyente - más centrada en lo que puede ser desarrollado por el sujeto que en lo que lo funda-, "subjetividades que no generan relaciones ni crean entramados" 
(Martínez, 2006, p. 144), que se evidencian prefiguradas para la reproducción y develan un sujeto desvalorizado y desprovisto de poder. Para esta autora, pensar y revisar la subjetividad exige "desentrañar las interacciones que soportan su construcción, las condiciones sociales en que se ha desempeñado, las necesidades y luchas que ha tenido que cursar en el tiempo para construirse de otra manera.” (p. 145).

Como expresiones de nuevas búsquedas y configuraciones de nuevas subjetividades políticas en maestros, reconoce tres aspectos básicos: la historicidad y el reconocimiento de sí, que permiten repensar el quehacer pedagógico y los modos de ser y de actuar; la potenciación de una voluntad de acción social, gracias a la cual el sujeto se descentra de sí mismo y se distancia de lo impuesto, y, por último, la potenciación de la capacidad de acción colectiva, que le permite al maestro arriesgarse a actuar y aprender a hacer crítica.

Los antecedentes revisados evidenciaron la necesidad de reflexiones en relación con la configuración de los maestros como sujetos políticos desde la perspectiva de los maestros, además este rastreo sirvió para avanzar en la construcción de los referentes conceptuales que aportaron sentido a la investigación.

Para pensar la subjetividad política es necesario reconocer, desde la perspectiva de González Rey (citado en Díaz, 2007, p. 379), que la subjetividad se construye por medio de la historia de cada persona a partir de su trayectoria social, es decir que el contexto social va a tener una fuerte influencia sobre cómo el sujeto construye su subjetividad. En este sentido, interactuar con los otros va a crear en los sujetos la capacidad de reconocerse o desconocerse en otros, de aceptar o disentir los valores sociales establecidos, de sancionar o proponer.

El sujeto político se configura con los otros, reconociéndose como sujeto colectivo, pues la política es una acción en el "entre nos” que posibilita hablar entre iguales en el mundo común, que es el lugar de lo público, para tomar decisiones sobre lo que afecta a todos. En palabras de Arendt (2005), "la esfera pública surge de estar juntos, de compartir palabras y actos” (p. 224), lo cual permite construir proyectos históricos de transformación social, donde los sujetos políticos resignifiquen su cotidianidad con miras a vivir un mundo que reivindique las relaciones desde la solidaridad, la justicia, la equidad y la dignidad humana. En síntesis, el sujeto político se entiende como:

Un ser con conciencia histórica y juicio político para discernir y debatirse consigo mismo al momento de tomar decisiones, y resistir a las lógicas naturalizadas del mundo; con voluntad para actuar y agenciar el mundo, mediado siempre por la esperanza de otras formas posibles de hacerlo. Además, y como elemento fundamental, se reconoce en un mundo compartido donde no sólo están aquellos que hacen parte de su propia vida, dándole entonces un lugar de legítimo otro a aquellos con quienes comparte la existencia, y generando un sentido de responsabilidad y hospitalidad por esos otros y otras de la intersubjetividad. (García, Restrepo y Urrego, 2013, p. 51) 
En este sentido, para comprender cómo se configura la subjetividad política es necesario reconocer las relaciones intersubjetivas que posibilitan su constitución, pues "si todo sujeto se constituye por medio de otro, en la distinción del otro y en el reconocimiento del otro, no basta afirmar lo propio; es necesario entonces reconocer, delimitar, y agenciar lo propio y lo ajeno” (Lechner, citado en Martínez, 2006, p. 138). En la intersubjetividad se asientan las bases de la experiencia compartida y del mundo común, y además se construyen los sentidos y significados que articulan nuestra biografía.

La alteridad, como uno de los rasgos de la subjetividad política, es el modo de relación intersubjetiva que asegura la construcción del mundo común, pues entendida como la decisión de "responder éticamente a la existencia del otro" (Skliar, 2007, p. 67), permite la implicación del otro en el yo desde su igualdad y distinción, es decir, desde la pluralidad entendida como la condición básica de la vida política, con su doble carácter de igualdad y de distinción, que es la base primordial de la alteridad, pues sin el reconocimiento de todos y todas como sujetos de derechos, en igualdad de condiciones de dignidad y humanidad pero además, como seres únicos y diversos, será muy difícil dar una respuesta ética a esa otredad que me interpela y me confronta con la distinción.

Para Lévinas la alteridad es "la presencia del otro en el yo" (citado en Quesada, 2011, p. 397), la cual acontece en el acceso al rostro del otro, es decir, el otro se me presenta, se me da, mediante el rostro; el rostro no es la cara, el rostro es la huella del otro, es la presencia viva del otro, es un llamado que exige una respuesta. Esta respuesta a la demanda del rostro del otro es lo que Lévinas entiende como ética, una relación intersubjetiva que supone implicar a los otros en la propia subjetividad.

En este sentido, una subjetividad que se configura desde la alteridad rompe la idea de un sujeto que se constituye desde la mismidad, para convertirse en un sujeto con otro y para otro, es decir, en un sujeto ético. Esta idea de configurarse sólo a través de una relación de interdependencia con otros y otras, en donde se es sujeto siendo con los demás, implica la responsabilidad de estar concernido por el otro, lo que supone un cuidado responsable de sí y de los demás.

Estos referentes teóricos es necesario contextualizarlos en el marco de la escuela para comprender cómo la educación ha sido desvinculada de la política, y por tanto ha sido una práctica que busca reproducir la historia en vez de aprender cómo hacerla. Se trata, en palabras de Giroux (2006), de una educación pensada como artefacto que puede resumirse mediante las palabras “transmisión”, “imposición”, "fabricación”, pues los estudiantes son concebidos como un cuerpo unitario alejado de las fuerzas ideológicas y materiales que constituyen sus subjetividades. Se trata de una educación que se instala como instrumento de dominación de ideologías hegemónicas que restringen formas particulares de prácticas maestro-alumno. En palabras de Freire (2009), en esta educación bancaria: 
[...] el educador es siempre quien educa; el educando el que es educado. El educador es quien sabe; los educandos, quienes no saben. El educador es quien piensa; los educandos son los objetos pensados. El educador es quien opta y prescribe su opción; los educandos quienes siguen la prescripción (p. 32).

Esta educación, en la cual el saber, el pensar y el elegir corresponden al maestro, ofrece menos opciones al estudiante para desarrollar su conciencia crítica y reflexionar su mundo e insertarse en él como agente de cambio y transformación, como sujeto constituyente; la relación pedagógica es unilateral y vertical, de ahí que el diálogo y las experiencias dialécticas sean anuladas y por tanto la toma de conciencia se reduce a procesos de instrucción o de alienación que se alejan de la posibilidad del pensamiento crítico. Además, desde esta perspectiva educativa el pensamiento y la libertad de los estudiantes parecen peligrosos para las estructuras dominantes, que buscan en el control de los sujetos impedir la acción colectiva y la construcción de una esfera pública desde la acción y el discurso, constriñendo la pluralidad de los sujetos, homogenizando currículos, estandarizando formas de enseñanza e invisibilizando las múltiples maneras de enseñar y aprender.

Al negar estas condiciones humanas del discurso y la acción, se niegan todas las formas de organización política, pues según Arendt (2005), "actuar y hablar juntos son las condiciones de la política” (p. 228). Desde esta perspectiva, la política es entendida como una acción y no como una estructura, se trata de la más elevada y significativa de las actividades que definen la condición humana. Sostener desde la perspectiva de Arendt (2005) que la política es una acción, implica entenderla como la posibilidad de un nuevo comienzo, pues los seres humanos tienen la capacidad para actuar juntos, para emitir discursos y palabras, pero sobre todo tienen la posibilidad de cambiar las condiciones existentes. En palabras de Bedoya, Builes y Lenis (2009, p. 1257): "Actuar es tomar una iniciativa, comenzar, gobernar, poner algo en movimiento. Sin la presencia del discurso, la acción perdería su carácter revelador; mediante ellos, los sujetos muestran quiénes son, su identidad acontece en lo que hacen y dicen”.

La acción se inscribe en una esfera de pluralidad humana y es así la condición esencial de toda vida política, esa esfera pública de encuentro entre los demás, donde el otro me garantiza la realidad de mi existencia. La pluralidad, con su doble carácter de igualdad y distinción (Arendt, 2005), confirma que todos los hombres somos iguales en tanto podemos entendernos y prever para el futuro las necesidades de los que llegarán después, y a la vez confirma que todos somos distintos en tanto la configuración de nuestra identidad nos hace únicos, lo cual se refleja a través de nuestras acciones y discursos. La pluralidad se refiere a la posibilidad de vivir como ser distinto y único entre iguales (Arendt, 2005, p. 207), por lo que se convierte en la condición básica tanto para la acción como para el discurso.

Pensar la educación como una acción política entonces, implica introducir novedad a las formas de organización reinantes de la escuela, esto es, crear otras maneras de relación más democráticas que permitan a los estudiantes aparecer con su pluralidad 
desde su discurso y acción, para consolidar una esfera pública y un poder colectivo a partir de los cuales puedan configurarse sujetos que transforman la historia, no que la reproducen.

\section{Metodología}

Este ejercicio de investigación fue comprensivo, fundamentado en la fenomenología hermenéutica, pues se parte de la experiencia del sujeto para comprender el sentido que ésta tiene en su historia vital (Ricoeur, 2005). La principal estrategia metodológica fue la narrativa como el camino predilecto de explicación y comprensión del modo de ser de lo humano. La pregunta por la subjetividad es una pregunta fenomenológica, y la pregunta por el sentido de las experiencias en la configuración de esa subjetividad es hermenéutica. Es así como buscamos reconocer los acontecimientos narrados por los maestros, para comprender la manera como estos contribuyeron en la configuración de su subjetividad política.

Desde esta perspectiva narrativa y entendiendo sus múltiples posibilidades técnicas, se eligió el relato oral autobiográfico como el camino más apropiado para indagar por la subjetividad de los y las participantes, porque como lo plantea Luna (2004, p. 29), "la autobiografía ha ido de la mano de la historia oral en investigación y se ha convertido en una poderosa herramienta para indagar por la subjetividad".

Para hacer la selección de los participantes, las investigadoras identificaron algunos maestros y maestras que por sus prácticas pedagógicas podían reconocerse como sujetos políticos, que desde la perspectiva que se explicó en los referentes teóricos emprenden acciones de transformación en el aula. Fueron convocados diez maestros vinculados con el sector oficial de la ciudad de Medellín y siete participaron de un grupo focal. Luego del análisis de los discursos de los maestros durante el grupo focal, procedimos a invitar a cuatro, dos maestros y dos maestras, quienes aceptaron participar en las entrevistas conversacionales donde narraron su relato autobiográfico.

Este muestreo teórico o intencionado está centrado en la idea de que el número de casos para estudiar no es más importante que el potencial de cada caso para ayudar en el desarrollo de comprensiones sobre el tema en cuestión (Taylor y Bogdan, 1996). De esta manera, la recolección de datos estuvo guiada por la idea de acudir a personas o acontecimientos que maximizaran las oportunidades de descubrir variaciones entre los conceptos y que hicieran más densas las categorías en términos de sus propiedades y dimensiones (Strauss y Corbin, 2002).

Los maestros participaron en dos entrevistas de tipo conversacional, las cuales fueron grabadas con su permiso explícito en el consentimiento informado, se trascribieron y convirtieron en textos escritos, con inferencias iniciales por parte de las investigadoras, que posteriormente fueron devueltos a los respectivos narradores/ as para que pudieran leerse y hacer los cambios o las aclaraciones que consideraran pertinentes o necesarias. 
El análisis de los datos se hizo a partir de las lecturas e interpretaciones particulares de los relatos de cada participante; posteriormente se hizo un ejercicio de horizontalización que permitió encontrar puntos comunes y divergencias que permitieron hacer conjeturas frente a las condiciones que se requieren para que se configuren las subjetividades políticas, teniendo presente que lo que no era común también nos señalaba las múltiples vías por las que puede llegar a constituirse el sujeto político.

Finalmente se realizó la construcción del sentido de los datos alrededor de los cuatro rasgos de subjetividad política de los maestros participantes — pluralidad, conciencia histórica, resistencia y alteridad-, reconociendo los acontecimientos biográficos más importantes de sus vidas y las decisiones que han marcado el devenir de su existencia, pues en cada uno de los maestros emerge uno de los rasgos de la subjetividad política con más fuerza y a partir de allí se entretejen los demás rasgos.

\section{Resultados y discusión}

\section{La alteridad en las narrativas de los maestros}

A continuación se presentarán los hallazgos referidos a la alteridad en la narrativa de los maestros y la manera como se entretejen con la configuración de su subjetividad para hacer de la educación una acción política. Los relatos autobiográficos de los maestros expresan cómo la alteridad, o la responsabilidad ética por el otro, es vivida por cada uno de manera diversa en la escuela a partir de la forma como conciben y se relacionan con la otredad.

Para Felipe, uno de los maestros participantes, el otro es un sujeto con capacidad para autodeterminarse, agente y participante activo en la construcción de las soluciones y posibilidades, capaz de responsabilizarse de sus actos y tomar conciencia del alcance de sus acciones. En este sentido, para posicionar al otro como sujeto, desde la escuela, este maestro empieza a empoderarlo de su rol y les enseña a los niños y a las niñas a solucionar sus problemas cotidianos a través de la palabra, la resistencia y la creatividad.

Los niños del grupo cuando tienen problemas con otro, van aprendiendo, buscando maneras de solucionar el problema, o sea, no solamente quedándose ahí, sino también buscando mediación, hablando, entonces yo empiezo a darme cuenta de personas que están empezando a poner esos límites y a reconocer que tienen derechos específicos y que no tienen por qué ser vulnerados (Felipe, entrevista, 2013).

La responsabilidad por la existencia del otro, para este maestro, implica empoderarlo, acompañarlo a desarrollar capacidades para que resuelva problemas vitales y tome conciencia de su rol de agente constructor de nuevas posibilidades. 
En el caso de Manuel, el otro es un sujeto de reivindicaciones, por eso su lucha es por las poblaciones vulnerables, en este caso por los estudiantes de las comunas de la ciudad de Medellín que "necesitan ser rescatados de la guerra”, luchar por la garantía de sus derechos y reconocer permanentemente sus historias para reinventarlas y subjetivarlas. Su apuesta por aportar a los jóvenes una formación crítica, reflexiva y narrativa está fundamentada además en la idea de que son actores sociales que pueden y tienen también el deber de aportar a la construcción de nuevas formas de relación, entablando relaciones políticas con ellos, que los validan como sujetos políticos.

En este sentido, los vínculos que Manuel promueve con sus estudiantes tienen en su base el principio de la democracia, relacionada con formas equitativas de movilizar el poder y la autoridad en el aula. Para este maestro, educar implica un pensarse para otros, pensar acciones distintas a las tradicionales, inventar nuevas didácticas y metodologías para “encantar con el saber”, en un ejercicio permanente de "darse a los muchachos”, aportando vitalidad y esperanza, pues en la medida en que enseña también aprende nuevos sentidos y se va reconfigurando.

En el caso de Juana, el otro es quien tiene la capacidad de tomar postura, que puede ser coherente o incoherente, que puede quedarse en las apariencias o buscar las causas, que puede resistirse o quedarse callado. El otro, en este caso el estudiante de la Comuna 13, también es para ella quien necesita ser cuidado y acompañado por una maestra que le permita tomar conciencia de su realidad. En este sentido, Juana toma posición de cuidar del otro como una acción de resistencia, pues, como ella afirma, hay que inventarse otro camino para relacionarnos, ya que "no podemos seguir pensando que aprovechándonos del otro, que con tal de que a mí me vaya bien ya todo está bien" (Juana, Entrevista, 2013). Por esto en sus clases hace una apuesta por aportar a la formación de un sujeto integral, transformador y crítico, en oposición a la formación que se imparte actualmente en la escuela de un sujeto pasivo, que reproduce y no protesta, que todo le parece que está bien y cree que nada se puede transformar.

En los relatos de Amalia, la cuarta maestra, encontramos la alteridad como el primer principio ético en la configuración de su subjetividad, que se convierte en el rasgo central de su subjetividad política y potencia la aparición de la conciencia histórica, la pluralidad y la resistencia, motivo por el cual sus narrativas se analizan con mayor detalle.

En su historia vital hay una constante referencia a reconocer al otro como humano y a sentirse responsable de él. Para ella, el cuidado del otro no es solo un asunto de orden afectivo o asistencialista, sino que es un asunto que le permite la expansión de su proyecto vital, como maestra portadora de esperanza. Esta tendencia hacia el otro se convierte en un asunto político, porque en la intersubjetividad se establecen relaciones que desde el afecto, la solidaridad y el reconocimiento buscan transformar el poder hegemónico y construir relaciones igualitarias y abiertas a otras formas de entender el vínculo pedagógico. Esa respuesta ética a la existencia del otro se expresa de la siguiente manera, en las palabras de Amalia: 
Yo tengo que ser responsable con esos seres humanos, ese niño que yo tengo en las manos yo tengo que ayudar a que sus alas crezcan para que vuele, pero para que vuele bien, no para que vuele a medias o para que caiga en el primer intento, o para que haga lo que no debe hacer, yo siento esa responsabilidad con ellos, no puedo descuidar lo mío, pero sí tengo que ingeniármelas, detenerme y pensar en eso. (Amalia, Entrevista, 2013).

Esa responsabilidad por el otro surge ante experiencias vitales como la orfandad y el empobrecimiento, que ella misma relata como los asuntos que después de resignificarlos le han permitido tomar conciencia del mundo y del otro para intentar comprenderlo desde su propia humanidad. En esas condiciones estuvo acompañada por el abuelo y la familia extensa que le ayudaron a sobrellevarlas, sin embargo, dichas situaciones se convierten en un hito importante en su historia a partir del cual aprende a mirar las realidades humanas, y así configura una forma de comprender el mundo y advierte su necesidad de humanización. Amalia en su adolescencia sale de su esfera privada, de la casa del abuelo cuidador y protector, al escenario público de la vecindad con la intención de hacer algo por el "vecino que se encuentra enfermo, desmotivado o con ganas de hablar".

El otro, en este caso, era cualquier alguien que tenía una dificultad, pero también era otro con el que estaba configurando su subjetividad, pero no una subjetividad autónoma sino, más bien, una subjetividad desde la heteronomía, que ya no se somete a la voz de su propia razón para construirse, sino más bien que se hace responsable de la vida del otro y se construye comunitariamente. Este descubrimiento del otro en la vida de Amalia permite que la configuración de su subjetividad sea desde la alteridad y no desde la mismidad, es decir, una subjetividad que se construye desde los otros, en los otros y para los otros.

La alteridad hace que Amalia tome conciencia del mundo y de la historia, y desde niña se expresa a través de interrogantes sobre la equidad, la justicia y la verdad, como, “¿Por qué unos tienen más qué otros? ¿Por qué a esta casa no llegó el niño Dios y donde el vecino, sí?". Esta conciencia del mundo es otro de los rasgos de la subjetividad política que le permite inquietar, preguntar, tomar distancia y observar críticamente las relaciones en las que se ha configurado y además reconocerse como parte de una historia que es compartida, que le precede, la constituye y de la cual también es responsable; historia que además de permitirle reconocer la manera como se ha configurado su subjetividad a lo largo del tiempo, le revela las relaciones intersubjetivas de poder y desigualdad en las cuales se ha configurado como ser humano. Por ello, en las relaciones con sus estudiantes busca desarrollar reflexiones que los lleven a una conciencia crítica sobre las formas hegemónicas de poder que son recurrentes en sus historias personales, pues, como ella lo sostiene, "no debemos dejar de preguntarnos por el funcionamiento del mundo". 
Con estos interrogantes sobre el funcionamiento del mundo elige ser maestra, motivada por la posibilidad de estar con otros en relaciones de alteridad, identificada con sus tías maestras que siempre estaban rodeadas de estudiantes, y en busca de un espacio donde se pueda ser con otros y acompañarlos en sus procesos de transformación. Su práctica pedagógica inicia marcada por la violencia en uno de los municipios de Antioquia y más tarde en Medellín en una de las comunas más violentas de la ciudad. Enseñar en medio de esas situaciones de violencia le da una visión del contexto, de la realidad social, política y económica de las comunidades y de los estudiantes en específico. Esas experiencias le han permitido comprender, según ella, que la miseria y la injusticia producen más violencias, pero también le han ratificado la necesidad de sentirse solidaria con el dolor y el sufrimiento del otro y de creer profundamente en la educación como una esperanza de transformación.

Estas experiencias de violencia de los años noventa y la lucha por los territorios que enfrentaron las comunas de Medellín en los años que siguieron, además de solidarizarse con el dolor del otro, le han permitido entenderlo, identificarse con él, considerarlo en igualdad de condiciones y tratarlo como un ser humano:

Yo considero que tengo la capacidad de tratar al estudiante como un ser humano igual a mí, y eso al joven le da tranquilidad, le da confianza, le da un poquito de paz en su interior, obvio que uno sí tiene que manejar su autoridad como docente, pero también saber que ese ser humano que está ahí es igual a mí, que somos lo mismo, sólo que la condición de él es estudiante y la mía es ser docente (Amalia, Entrevista 2013).

Es así como puede evidenciarse el reconocimiento que Amalia hace del otro como alguien igual, lo cual genera confianza y tranquilidad en la vida de sus estudiantes, pero además es capaz de reconocer la irreductible singularidad humana para acompañar el proceso formativo. Esto es, capacidad para reconocer la pluralidad humana, entendida con Arendt (2005) como:

La condición humana por excelencia, la cual no sólo es la condición sin la que no habría una vida política, sino que es la condición por la cual es posible toda vida política, hace referencia a la igualdad que compartimos como especie, como humanos y a la distinción que nace de la diferencia, del ser únicos, del tener historias distintas y del ser y estar en el mundo de una manera particular (citado en García, Restrepo y Urrego, 2013, p. 106).

En este sentido, vivenciar la pluralidad humana como otro de los rasgos de la subjetividad política y como fundamento de la configuración del sujeto, es lo que la hace una maestra distinta a las demás, pues el respeto y la equidad que viven sus estudiantes en clase empiezan a ser factores centrales en la configuración de sus subjetividades. De esta manera, la pluralidad le permite a Amalia asumir el reto del cuidado del otro como base fundamental de su acción educativa, entendiendo la educación como una experiencia de hospitalidad y como una práctica de acogida, que se constituye en una forma de resistencia a la sociedad injusta y capitalista en la que vivimos. 
La resistencia, entendida como la forma de enfrentarse a lo preestablecido para construir nuevas subjetividades libres de las predeterminaciones de la sociedad, es otro de los rasgos de la subjetividad política, y en la vida de Amalia surge al reconocer el funcionamiento injusto del mundo y la deshumanización del sujeto. Esta resistencia se expresa como cuestionamiento al individualismo, materialismo y egocentrismo reinantes y en oposición a las formas de relación basadas en el egoísmo y la competencia. Su forma de resistencia es desde la alteridad, y busca que sus estudiantes tomen conciencia del mundo en el que viven y se posicionen políticamente frente a él.

Así, pues, podríamos decir con los participantes de la investigación que ser político es pensarse en una perspectiva colectiva, lo que va unido al cuidado responsable de los otros con los que habito el mundo, y estar convencido de que mi acción es necesaria e incide en el mundo y en la historia. La política es con otros, no es en soledad, y es promoviendo y haciendo efectivos los principios morales de los que se habla; hacer política es hacer justicia.

Ser político es compartir, es ser justo, es saber de las necesidades de los otros, el ser político piensa no tanto para sí, piensa que se mueve alrededor de un mundo que le necesita para que ese mundo salga adelante, por ese lado es que se debe mirar la política, porque no tiene sentido de otra manera (Amalia, Entrevista, 2013).

El maestro que se asume como sujeto político es capaz de implicarse en los procesos de formación de los y las estudiantes, no como resultado de criterios, juicios o estándares, sino más bien como una predisposición subjetiva que va más allá de todo contrato. Implicarse significa ver al otro en condición de igual, sin limitar su irreductible singularidad, lo que conlleva pensar nuevas maneras de construir el vínculo educativo desde la hospitalidad y el cuidado del otro.

\section{Conclusiones}

Pensar la subjetividad política a partir de los hallazgos de la investigación supone reconocer un proceso de configuración permanente, que a través de los acontecimientos biográficos posibilita la emergencia de cuatro rasgos en la biografía de los maestros participantes: pluralidad, conciencia histórica, resistencia y alteridad, los cuales le permiten al sujeto político tomar conciencia de que el mundo es compartido, resistirse a la injusticia y a los modos de relación reinantes, reconocer al otro desde su igualdad y distinción para acogerlo y fundar con él un proyecto de sociedad en donde el objetivo sea construir el mundo común.

La configuración de la subjetividad política parte de experiencias vitales que permiten implicar al otro en el yo, lo cual requiere descentrarse del sí mismo, movilizar esquemas de pensamiento fundamentados en el egocentrismo y la individualidad a fin de construir nuevos esquemas, en los que la fraternidad y la solidaridad afecten las formas de pensar y construir la realidad social. 
Por consiguiente, las relaciones intersubjetivas basadas en el principio ético de la alteridad transcienden las leyes jurídicas que declaran que todos los seres humanos somos iguales en dignidad y derechos, para declarar que soy responsable de la existencia del otro no solo porque seamos iguales ante la ley, sino también porque somos distintos y su alteridad asegura mi singularidad. En este sentido, el sujeto político asume al otro en su radical novedad, con capacidad de emprender acciones nuevas y expresar sentidos diversos, y admitiendo que escapa de mi capacidad de control y dominación, por eso las relaciones de alteridad se fundamentan en la necesidad de ensanchar el espacio de la mismidad para que el otro, con la enteridad de su existencia, pueda afectarlo, confrontarlo, cuestionarlo y, de ese modo, acompañarlo a un devenir permanente.

La acción educativa desde la alteridad implica tomar decisiones en el horizonte moral, plantearse la orientación al bien como bien común, en el que el respeto, la justicia y la dignidad humana sean el sustrato moral de las relaciones con los estudiantes. No hay reconocimiento del otro sin amor como fuerza que aglutina, por eso la alteridad pone en escena todo el potencial afectivo, la capacidad de amar y de cuidar del otro, de sí y del entorno.

En esta dirección, y para pensar la acción educativa como acción política, consideramos con Freire que es imposible enseñar sin la capacidad forjada, inventada y bien cuidada de amar. Como señala el autor, "es preciso atreverse a hablar de amor sin temor de ser llamado blandengue, o meloso, o anticientífico” (Freire, 2004, p. 8). Lo anterior no implica entregarse amorosamente en un proceso de afirmación y aceptación del otro, sino básicamente establecer relaciones educativas que permitan al sujeto su humanización, acceder a su vocación ontológica de ser más, lo que no es otra cosa que desarrollar sus capacidades en plenitud para crear, para transformar y pronunciar el mundo, para relacionarse con otros y otras; en definitiva, para superar las condiciones históricas de opresión.

La responsabilidad por el otro es vivida por los maestros participantes como la posibilidad de empoderar a los niños y niñas y jóvenes de capacidades para resolver sus conflictos a través de las palabras, como el caso de Felipe; cuidar del otro implica para Manuel la necesidad de entablar relaciones democráticas y justas en el aula; para Juana esa responsabilidad por el otro se expresa como la posibilidad de acompañar a los estudiantes a tomar conciencia de su realidad para no reproducirla, sino más bien para transformarla. En el caso de Amalia, hacerse cargo de la existencia del otro implica reconocer el dolor del otro, para hacer justicia. En este sentido, relacionarse desde la alteridad no es un asunto meramente afectivo o asistencialista sino más bien político, porque permite la construcción de vínculos educativos que desde el reconocimiento, la solidaridad y la acogida permiten la acción conjunta de estudiantes y maestros para construir los objetivos de formación, las metodologías de aprendizaje y las formas de relación democráticas desde las cuales se emprenden acciones de transformación colectiva. 
Así, la alteridad entendida como una relación ética de cuidado y de atención amorosa para con el otro, es una vía para la configuración de subjetividades políticas que se tejen con otros para emprender acciones que conlleven la transformación de las tramas de relación y poder, lo que requiere cambiar condiciones microestructurales para acceder a una vida más digna, justa y equitativa. En este sentido, la alteridad se trata de un asunto ético, pero también político, de una apuesta decidida por ser responsable de la vida del otro como una forma de resistencia al egoísmo y la cosificación del sujeto que presenta esta época, a fin de construir juntos espacios comunes en donde se puedan emprender acciones colectivas que empiecen por transformar la cotidianidad, reconociendo las diversas y polifónicas maneras de habitar el mundo, en contraposición a los totalitarismos que desagregan la capacidad de acción colectiva.

Finalmente, estas conclusiones y hallazgos dejan las puertas abiertas para pensar los procesos educativos de los maestros y las apuestas por la formación política de las universidades en sus currículos. De ahí que algunas nuevas preguntas que surgen de estas reflexiones puedan ser: ¿Cómo aporta la formación universitaria a la configuración de los maestros como sujetos políticos? ¿Cuáles son las apuestas políticas en la formación de maestros que tienen las facultades de educación? ¿Cómo aportar a la configuración de subjetividades políticas de maestros que tejan formas de relación desde la justicia y la paz?

\section{Referencias}

Alvarado, S. V., Ospina, H. F., Botero, P. y Muñoz, G. (2008). Las tramas de la subjetividad política y los desafíos a la formación ciudadana en jóvenes. Revista Argentina de Sociología, 6(11), 19-43.

Arendt, H. (2005). La condición humana. Barcelona: Paidós.

Barilá, M. I., Fabbri, S. y Castillo, A. (2008). La reflexión de los docentes sobre su práctica en los espacios institucionales de una escuela media nocturna. Educación, Lenguaje y Sociedad, 9(5), 1-10

Bedoya, M. Builes, M y Lenis, J. (2009). La acción educativa como acción narrativa. Revista Latinoamericana de Ciencias Sociales, Niñez y Juventud, 7(2), 12551271.

Díaz, A. (2007) Subjetividad: una perspectiva histórico cultural. Conversación con el psicólogo cubano Fernando González Rey. Univ. Psychol, 4(3), 373-383.

Díaz, Á. e Inclán, C. (2001, enero-abril). El docente en las reformas educativas: Sujeto o ejecutor de proyectos ajenos. Revista Iberoamericana de Educación, (25), 17-41.

Freire, P. (2004). Cartas a quien pretende enseñar. Buenos Aires: Siglo XXI Editores.

Freire, P. (2009). Pedagogía del oprimido. La Habana: Caminos.

García, D., Restrepo, L. y Urrego, A. (2013). Sentidos entretejidos: Una aproximación a la subjetividad política en maestros y maestras (Tesis de maestría). CINDE, Universidad de Manizales, Medellín. 
Giroux, H. (2006). La escuela y la lucha por la ciudadanía. México D. F.: Siglo XXI Editores.

Honneth, A. (1997) La lucha por el reconocimiento: por una gramática moral de los conflictos sociales. Barcelona: Crítica.

Loyo, A. y Rodríguez, M. (2007). Maestras activistas de la ciudad de México. Subjetividad y contextos de interacción. Revista Mexicana de Sociología, 69(1), 139-168.

Luna, M. (2006). La intimidad y la experiencia en lo público. (Tesis de doctorado). CINDE, Universidad de Manizales, Medellín.

Martínez, C. (2006). Disquisiciones sobre el sujeto político. Pistas para pensar su configuración. Revista Colombiana de Educación, (50), 106-121.

Mèlich, J. (2000). Narración y hospitalidad. Revista Análisi. (25), 129-142.

Mèlich, J. (2007). La formación inquietante de la memoria. En J. Larrosa, Entre nosotros, la convivencia entre generaciones (pp. 85-94). Barcelona. Fundación Viure i Conviure.

Mórtola, G. (2006, diciembre). Una aproximación narrativa a la construcción de la identidad laboral docente. Algunos aspectos biográficos previos a la formación. Educación, Lenguaje y Sociedad, 4(4), 83-104

Patiño y Rojas (2009). Subjetividad y subjetivación de las prácticas pedagógicas en la Universidad. Educación y educadores, 12 (1), 93-105

Poujol, G. (2004). Objetividad y subjetividad en la configuración de la eticidad en un grupo de profesoras. Revista Latinoamericana de Estudios Educativos, 34 (4), 69-105.

Prada, M. Ruíz, A., Gómez, J., Herrera, M., Echavarría, C., López, L. y Ortiz, G. (2006). Subjetividades políticas: apuestas en investigación pedagógica y educativa. Bogotá: Universidad Pedagógica Nacional, Instituto Nacional de Pedagogía.

Quesada, B. (2011). Aproximación al concepto de "alteridad" en Lévinas. Propedéutica de una nueva ética como filosofía primera. Investigaciones Fenomenológicas, (3), 393-405.

Ricoeur, P. (2005). Del texto a la acción. México: Fondo de Cultura Económica.

Roldán, O. (2006). La institución Educativa: Escenario de Formación Política que se configura desde el ejercicio mismo de la política. Medellín: Universidad Autónoma de Manizales- CINDE.

Skliar, Carlos (2007). Notas para pensar la convivencia, la hospitalidad y la educación. En J. Larrosa, Entre nosotros, la convivencia entre generaciones (pp. 67-84). Barcelona: Fundación Viure i Conviure.

Strauss, A. y Corbin, J. (2002). Bases de la investigación cualitativa: técnicas y procedimientos para desarrollar la teoría fundada. Medellín: Universidad de Antioquia.

Taylor, S. y Bogdan, R. (1996). Introducción a los métodos cualitativos de investigación. Barcelona: Paidós. 